- RAHIIS, Revista de Administração Hospitalar e Inovação em Saúde Vol. I8, n.3. Belo Horizonte, MG " UL/SET 202I "e-ISSN: 2177 2754 e ISSN impresso: 1983-5205 " DOI: https://doi.org/I0.21450/tahis.vI8i3.6706" Submetido: (28/0I/2021) = Aceito: (03/I0/202I,

- Sistema de avaliação: Double Blind Review "p. 22-38.

\title{
CONDIÇÕES DE TRABALHO DE PROFISSIONAIS DA SAÚDE: UM ESTUDO REALIZADO EM UM HOSPITAL PÚBLICO NO NOROESTE DO PARANÁ
}

WORKING CONDITIONS IN HEALTHCARE PROFESSIONALS: A STUDY PERFORMED AT A PUBLIC HOSPITAL IN THE NORTHWEST OF PARANÁ

CONDICIONES DE TRABAJO DE PROFESIONALES DE LA SALUD: ESTUDIO REALIZADO EN UN HOSPITAL PÚBLICO DEL NOROESTE DE PARANÁ

Cristiane Marques de Mello Docente - FACET - Faculdade de Ciências Sociais e Aplicadas do Paraná, Doutoranda em Administração pela Universidade Positivo - UP mellcris@gmail.com

Henrique Vilas Boas Nascimento Centro Universitário Integrado henriquevbn@gmail.com

Carolina Queiros de Albuquerque

Centro Universitário Unicesumar carolina.albuquerque@unicesumar.edu.br 


\section{RESUMO}

O principal objetivo do presente artigo é o de identificar como as condições de trabalho afetam a realização das tarefas diárias dos profissionais da saúde, especificamente da equipe de enfermagem. $\mathrm{O}$ estudo caracteriza-se como exploratório e descritivo, e utiliza-se de métodos qualitativo e quantitativo. A coleta de dados foi realizada por meio de um questionário com escala likert de sete pontos. Os respondentes do estudo foram enfermeiros e técnicos de enfermagem de um hospital público localizado no noroeste do Estado do Paraná. Os resultados apontam nem sempre é possível seguir à risca todos os protocolos e procedimentos-padrão, devido à falta de tempo, ocasionado pela grande quantidade de pacientes a serem atendidos. Os resultados mostram que há um grande percentual de profissionais que consideram estar no lugar certo, exercendo a profissão certa. É importante considerar que alguns entrevistados já tiveram depressão por conta da profissão. A satisfação dos profissionais da enfermagem está especialmente vinculada à cura dos pacientes, à gratidão recebida dos mesmos e de suas famílias, à oportunidade de ouvi-los e de serem considerados amigos desses pacientes.

PALAVRAS-CHAVE: Profissionais da saúde; Condições de trabalho; Hospital público.

\section{ABSTRACT}

The aim of this article is to identify how working conditions affect health professionals' daily tasks, specifically the nursing team. The study is characterized as exploratory and descriptive, and uses qualitative and quantitative methods. Data collection was performed using a seven-point Likert scale questionnaire. The study respondents were nurses and nurse technicians from a public hospital located in the northwest of the State of Paraná. The results show that it is not always possible to strictly follow all protocols and standard procedures, due to the lack of time, caused by the large number of patients to be treated. Regarding the work performed, results show that there is a large percentage of professionals who consider themselves to be in the right place, practicing the right profession. It is important to consider that some interviewees have already experienced depression due to their profession. The satisfaction of nursing professionals is especially linked to patients' healing, the gratitude received from them and their families, the opportunity to listen to them and to be considered friends of these patients.

KEYWORDS: Health professionals; Working conditions; Public hospital.

\section{RESUMEN}

El objetivo principal de este artículo es identificar cómo las condiciones de trabajo afectan el quehacer cotidiano de los profesionales de la salud, específicamente del equipo de enfermería. El estudio se caracteriza por ser exploratorio y descriptivo, y utiliza métodos cualitativos y cuantitativos. La recopilación de datos se realizó mediante una encuesta con escala Likert de siete puntos. Los encuestados del estudio fueron enfermeros y técnicos de enfermería de un hospital público ubicado en el noroeste del Estado de Paraná. Los resultados muestran que no siempre es posible seguir estrictamente todos los protocolos y procedimientos estándar, debido a la falta de tiempo, provocada por la gran cantidad de pacientes a tratar. Los resultados muestran que existe un gran porcentaje de profesionales que se consideran en el lugar adecuado, ejerciendo la profesión adecuada. Es importante considerar que algunos de los entrevistados ya han experimentado depresión debido a su profesión. La satisfacción de los profesionales de enfermería está especialmente ligada a la curación de los pacientes, la gratitud que reciben de ellos y de sus familiares, la oportunidad de escucharlos y ser considerados amigos de estos pacientes.

PALABRAS CLAVE: Profesionales de la salud; Condiciones de trabajo; Hospital público.

\section{INTRODUÇÃO}

As condições de trabalho dos profissionais da saúde têm sido tema de diversos estudos desenvolvidos ao longo dos anos, como por exemplos, Oliveira Jr. et al (2013), investigaram as Equipes 
de Saúde da Família (ESF) do município de Petrolina-PE, no que se refere às condições físico-estruturais, à qualidade dos serviços de saúde prestados à população, e aos problemas enfrentados no processo de trabalho. Costa, Borges e Barros (2015), realizaram um estudo com o intuito de avaliar a relação entre saúde psíquica e condições de trabalho de profissionais de saúde em dois hospitais da Universidade Federal do Rio Grande do Norte/UFRN. O trabalho de Boeck et al. (2019), buscou identificar os riscos que a sobrecarga de trabalho na enfermagem pode gerar para a segurança do paciente, sob a perspectivas dos profissionais da enfermagem.

Ressalta-se também o estudo de Wagner et al. (2019), que foi realizado em dois hospitais universitários alemães com o objetivo de detectar diferenças entre enfermeiros e médicos, em relação às percepções sobre condições psicossociais de trabalho; liderança, clima de segurança do paciente e clima de segurança ocupacional. O trabalho de Dias (2015) convida o leitor a refletir sobre as condições de trabalho e a saúde dos médicos. Na opinião da autora, o tema ainda tem sido pouco explorado na literatura e negligenciado no exercício da profissão. A menção desses trabalhos relatados nos dois primeiros parágrafos, tem o intuito de situar o leitor sobre as pesquisas similares já realizadas.

Desse modo, o presente estudo visa contribuir com pesquisas relacionadas ao tema, incluindo a investigação das condições de trabalho dos técnicos em enfermagem e enfermeiros(as), dentro de um hospital.

Esse estudo tem como uma de suas justificativas, a importância dos profissionais da saúde para o atendimento à população que necessita desses serviços constantemente. Os profissionais da saúde enfrentam diariamente uma jornada estressante de trabalho, e o estresse, conforme ressaltam Barcaui e Limongi-França (20I4), pode ser considerado um tema atemporal, que envolve o contexto social e situacional dos trabalhadores no processo laboral. Da mesma forma que podem existir fatores negativos na saúde do trabalhador, em relação às condições de trabalho, também pode existir um reflexo disso na precariedade do sistema de saúde (MACIEL; SANTOS; RODRIGUES, 20I5).

O principal objetivo do presente artigo é o de identificar como as condições de trabalho afetam a realização das tarefas diárias dos profissionais da saúde. Para tanto, procurou-se como objetivos específicos: investigar as relações entre colegas de trabalho, e entre chefia e subordinados, no que se refere à comunicação, tratamento pessoal, e cooperação no trabalho; descrever a percepção dos profissionais em relação à oportunidade de crescimento profissional; identificar possíveis problemas nas tarefas diárias desses profissionais; e analisar os fatores que causam satisfação no trabalho.

Por meio da pesquisa, será possível identificar os principais problemas que ocorrem durante a execução do trabalho desses profissionais, bem como os fatores que lhes proporcionam satisfação no desempenho de suas tarefas. E, a partir disso, os gestores poderão planejar formas mais eficientes para realização do trabalho.

\section{CONDIÇÕES DE TRABALHO}

Desde as reformas no setor da saúde até o final dos anos 1980 e ainda no decorrer dos anos 1990, que a precariedade da força de trabalho parece ter diminuído. No entanto, isso não quer dizer que estamos diante de um cenário extremamente satisfatório, nem em termos de emprego nem de condições de trabalho. Isso porque surgem novos problemas e muitos dos problemas antigos continuam, o que permite afirmar que o conjunto de condições de trabalho e saúde continua sendo uma questão urgente a ser resolvida pelo pessoal do setor de saúde (ORGANIZAÇÃO PANAMERICANA DA SAÚDE, 2012).

Estudos recentes têm demonstrado que as condições de trabalho em hospitais públicos não são satisfatórias (MANYISA; VAN ASWEGEN, 2017). Os resultados da pesquisa no Brasil realizada pela Organização Panamericana da Saúde (2012), apontam que mais da metade de médicos e enfermeiros afirmam que as condições de trabalho em hospitais não são boas. No estudo realizado por Canales- 
Vergara, Valenzuela-Suazo e Paravic-Klijn (2016), sobre as condições de trabalho e os motivos pelos quais os profissionais de Enfermagem no Chile adoecem, aparecem como as principais problemáticas associadas ao trabalho da equipe de enfermagem: o estresse e a fadiga. Tal estresse estaria associado à insuficiência de recursos humanos diante do constante aumento da carga de trabalho. Esse cenário tornase ainda mais preocupante ao considerar que os ambientes de trabalho são caracterizados pela falta de recursos humanos e materiais, onde o profissional da saúde trabalha por longas horas, o que pode ocasionar condições crônicas de estresse. Essa realidade concorda com o exposto por algumas investigações realizadas no Brasil, conforme aponta os autores, da mesma forma fica evidente a presença de ambientes com sobrecarga de trabalho, longas jornadas de trabalho e falta de recursos. Essas condições de trabalho, aumentam a probabilidade de os profissionais da saúde adoecerem.

No estudo realizado pela Organização Panamericana da Saúde (2012), os resultados mostram que pelo menos metade dos profissionais sente sua saúde afetada pelas condições de trabalho, pelo horário, por um forte sentimento de indiferença ou (não) reconhecimento da tarefa realizada pelos superiores ou pelos sistemas institucionalizados. A persistência de más condições de trabalho, a baixa hierarquia dada ao sujeito, acompanhada da baixa autonomia para a gestão do trabalho, representam um conjunto de problemas que têm um impacto constante na qualidade dos cuidados da saúde.

A não adequação das condições de trabalho, o acelerado ritmo das atividades laborais, os entraves nos relacionamentos socioprofissionais, a imposição por resultados e o pouco poder para tomada de decisão de profissionais de enfermagem, podem influenciar qualidade de vida e a eficácia do trabalho (MARQUES et al., 20I5). O estresse causado por esses fatores, pode gerar problemas de saúde. No estudo realizado por Elias e Navarro (2006), foi confirmada a relação entre o estresse vivenciado no trabalho e as complicações ou agravamentos no estado de saúde de profissionais de enfermagem.

Muitos desses problemas podem colocar a segurança do paciente em risco. Promover a segurança do paciente e do trabalho estão entre os principais desafios para os hospitais (WAGNER et al., 2019), por isso, faz-se necessário conhecer as condições de trabalho dos profissionais da saúde, a fim de que haja aprimoramento na execução dos processos e melhor planejamento de gestão pelos membros do corpo diretivo desses hospitais.

Resultados do estudo de Wagner et al. (2019), apontam a necessidade de medidas para melhorar as condições psicossociais de trabalho dos profissionais de saúde nos hospitais, com ênfase especial nas melhorias para os enfermeiros. A redução de altas demandas quantitativas e de conflitos de papeis, é necessária para melhorar as condições psicossociais de trabalho dos profissionais de saúde. O estudo de Oliveira e Pedraza (2019) demonstra resultados positivos, da perspectivas de enfermeiros(as), no que se refere à estrutura das unidades de saúde, ao contexto de trabalho e à satisfação desses profissionais. Mas, a pesquisa aponta que existem críticas condições na organização do trabalho que causam insatisfação desses profissionais, e não são poucos os fatores que influenciam a rotina desses trabalhadores.

\section{FATORES QUE INFLUENCIAM A ROTINA DOS TRABALHADORES DA SAÚDE}

São muitos os fatores que provocam insatisfação dos trabalhadores da saúde e influenciam no dia a dia das atividades laborais desses profissionais.

Como alguns fatores que afetam a rotina de profissionais de saúde encontram-se: ambiente de trabalho desgastante, disputas internas, escassez de leitos que gera sobrecarga nas enfermarias; sobrecarga de trabalho e condições de trabalho precárias (ELIAS; NAVARRO, 2006).

Os fatores de insatisfação no trabalho de profissionais da saúde encontrados na pesquisa de Soratto et al. (2017) estão relacionados à gestão, ao relacionamento entre profissionais e pacientes e à sobrecarga de trabalho, devido à demanda excessiva. A sobrecarga de trabalho, conforme ressaltam Carvalho et al. (2017), provoca prejuízos à saúde dos profissionais de enfermagem, à organização no qual 
trabalham, bem como à assistência segura ao paciente (como por exemplo, administração errada de medicamentos aos pacientes, como apontado no estudo de Boeck et al. (2019).

Em um estudo realizado no Chile, observou-se que a precariedade, a demanda de trabalho, a organização do trabalho e os recursos limitados são condições que os trabalhadores de enfermagem vivenciam com frequência. Da mesma forma, os problemas de estresse, fadiga e esgotamento são os mais evidentes, e são os mesmos que provavelmente respondem às condições limitadas de trabalho, e está longe das condições de trabalho decente que se busca implementar. (CANALES-VERGARA; VALENZUELA-SUAZO; PARAVIC-KLIJN, 2016).

O trabalho publicado por Manyisa e Van Aswegen (2017) aponta que os principais preditores de insatisfação no trabalho dos profissionais da saúde são excesso de carga de trabalho, turnos irregulares e longas jornadas de trabalho, que ocasionam altos níveis de desgaste e exaustão emocional entre esses profissionais. Os autores afirmam ainda que é papel dos gestores, encontrar uma forma de lidar com essas questões para amenizar as consequências geradas, tendo em vista que as condições de trabalho insatisfatórias têm impacto negativo no bem-estar físico e psicossocial dos funcionários. A pesquisa de Beck et al (2019) apontou que para resolver problemas de sobrecarga, por exemplo, seria necessário adequar quadro de profissionais, ter reconhecimento profissional e também deveria haver uma valorização monetária na profissão.

Sobre a equipe gerencial do hospital, Wagner et al (2019) apontam que é necessário que a gerência do hospital se torne mais visível, especialmente para os enfermeiros, e que a comunicação entre a gerência do hospital e a equipe de enfermagem seja aprimorada. Os resultados mostram que altas demandas quantitativas devem ser reduzidas e também que a contratação de pessoal adequado pode contribuir para melhorar a segurança do paciente.

Ainda sobre a gestão, Oliveira e Pedraza (2019), enfatizam sobre a necessidade de adotar modelos de gestão que sejam mais democráticos, e que desenvolvam estratégias para promover o bem-estar dos profissionais, contribuindo para a execução eficaz dos processos de trabalho.

Para a Organização Panamericana da Saúde (20I2), é necessário identificar 'parceiros' estratégicos que ofereçam financiamento e seus conhecimentos, como institutos de pesquisa que estudam esse problema, que possam contribuir com metodologias e instrumentos, além de experiências no desenvolvimento de programas de saúde para profissionais de saúde, gestão de empregos e iniciativas de proteção social para profissionais de saúde.

Manyisa e Van Aswegen (2017) identificaram algumas estratégias que ajudarão a mitigar as barreiras às boas condições de trabalho, como:

- acesso aos recursos (financeiros e materiais) para execução das tarefas no prazo;

- fornecimento de infraestrutura adequada;

- preenchimento de cargos vagos;

- oferta de melhores pacotes de remuneração e incentivos;

- oportunidades de progressão na carreira;

- aprendizado ao longo da vida;

- flexibilidade horários de trabalho;

- adoção e desenvolvimento de políticas que promovam lealdade e retenção;

- melhorar a comunicação e o relacionamento interpessoal entre a gerência e a equipe; e

- melhorar e adequar a alocação de recursos.

Tais fatores poderão não apenas melhorar as condições de trabalho dos profissionais da saúde, que lidam com a grande demanda de pacientes e com o desafio de manter seu próprio bem-estar (BRUNETTO; XERRI; FARR-WHARTON, 2020), como também contribuir para criar um ambiente propício ao atendimento de alta qualidade ao paciente. 


\section{PROCEDIMENTOS METODOLÓGICOS}

O estudo é exploratório e descritivo, e utiliza-se de métodos quantitativo e qualitativo. Como instrumento de coleta de dados, foi elaborado um questionário com a utilização da escala likert, de sete pontos, que vai desde 'discordo totalmente' até 'concordo totalmente'. A coleta de dados foi realizada nos três períodos (manhã, tarde e noite), a fim de que os resultados tenham maior validade e confiabilidade, oportunizando às equipes dos três turnos, a participação no estudo.

A pesquisa foi realizada com os enfermeiros e técnicos de enfermagem de uma Santa Casa localizada no noroeste do Estado do Paraná. A coleta de dados foi realizada nos meses de Julho, Agosto e Setembro de 2019, nos três turnos de trabalho, manhã, tarde e noite. Os turnos estão divididos do seguinte modo: manhã das 7 hOO às I3h00; tarde das I3h00 às I 9 h00 e noite das $I 9 h 00$ às 7 h00 do dia seguinte. Algumas informações referentes aos trabalhadores investigados, foram obtidas nos meses iniciais do ano de 2020, junto à pessoa responsável pelo setor. Os critérios para seleção dos respondentes, foram os seguintes: ser atendente do SUS (Sistema Único de Saúde); estar interessado e ter disponibilidade para responder ao questionário.

Os respondentes foram I4 enfermeiros(as), 47 técnicos de enfermagem, 5 estagiários de enfermagem, apenas um questionário foi descartado (não considerado aqui) porque o respondente era um estagiário não remunerado, desenvolvendo um estudo para um trabalho de conclusão de curso, resultando num total de 66 questionários válidos. A idade média dos estagiários é de 20 anos, dos técnicos de enfermagem é de 34 anos e de enfermeiros(as) também é de 34 anos. Entretanto no que se refere aos técnicos de enfermagem há uma maior variação entre a menor e a maior idade dos profissionais, o profissional mais novo tem 2I anos e o mais velho 58.

Todos foram convidados a responder ao questionário, entretanto, nem sempre o profissional conseguia fazê-lo devido à demanda de trabalho, ou por conta de alguma situação emergencial. Os pesquisadores respeitaram todas as normas do hospital para realização da coleta de dados, bem como as normas éticas para realização do estudo.

Para a análise dos dados, foram utilizados o software SPSS 20 (Statistical Package for the Social Sciences), e o Excel, conforme será relatado mais detalhadamente na próxima seção.

Levando em consideração a questão ética da pesquisa com seres humanos, os participantes receberam esclarecimentos sobre os objetivos do estudo, bem como foram informados sobre como a pesquisa seria conduzida pelos envolvidos. Os participantes tiveram à disposição o Termo de Consentimento Livre e Esclarecido (TCLE). O projeto de pesquisa foi submetido à Plataforma Brasil e analisado pelo Comitê de Ética do Centro Universitário Integrado. O projeto foi aprovado, sob o número 3.367.498.

Além disso, houve também avaliação e aprovação do projeto pelo Comitê de Ética da Santa Casa na qual a pesquisa foi realizada.

\section{APRESENTAÇÃO E ANÁLISE DOS DADOS}

No que se refere à carga horária diária dos profissionais, trabalham 6 horas 54\%, trabalham 8 horas $6,1 \%$, e 12 horas $39 \%$ dos respondentes. Cerca de $36 \%$ dos trabalhadores tem outro emprego além do trabalho que exercem no hospital.

Conforme mencionado na metodologia, os resultados apresentados a seguir foram extraídos a partir da utilização do software SPSS 20 (Statistical Package for the Social Sciences). O Software Excel também foi utilizado na análise dos dados, especialmente na geração dos gráficos que serão apresentados nessa seção.

A tabela I, a seguir refere-se à frequência relativa e frequência absoluta das respostas. Nessa tabela colocamos siglas que se referem às respostas encontradas na pesquisa, DT é discordo totalmente; DG - 
discordo em grande parte; DP - discordo parcialmente; NCND - não concordo, nem discordo; CP concordo parcialmente; CG - concordo em grande parte; CT - concordo totalmente.

Considerando os resultados apresentados na tabela anterior, verificou-se que cerca de $50 \%$ dos entrevistados discordam (em algum grau) que o ambiente no qual trabalham seja um local tranquilo. Mais de $80 \%$ concordam que há (em parte ou totalmente) colaboração por parte de seus colegas, enquanto que 97\% (considerando concordo parcialmente; em grande parte e totalmente) se dizem ser colaborativos com seus colegas de trabalho. Existe um alto percentual de respondentes (mais de 85\%) que concordam que existe clareza sobre o que deve ser feito no seu trabalho diário, mas alguns discordam disso. Mais de $65 \%$ dizem que existem problemas de comunicação entre médicos e equipe de enfermagem. Cerca de $30 \%$ dizem discordar parcialmente ou totalmente que todos são tratados da mesma forma.

No que se refere ao reconhecimento do trabalho dos profissionais pelo chefe, $7 \mathrm{I} \%$ diz concordar parcialmente; em grande parte ou totalmente. Já a concordância (em algum grau) sobre o reconhecimento do trabalho realizado pelos pacientes é maior e representa cerca de $80 \%$. Esse resultado difere do estudo realizado pela Organização Panamericana da Saúde (2012), o qual aponta que no setor de enfermagem a falta de reconhecimento é alta, com resultados parecidos para Brasil e Argentina. 
Tabela I - Frequência relativa e Frequência absoluta

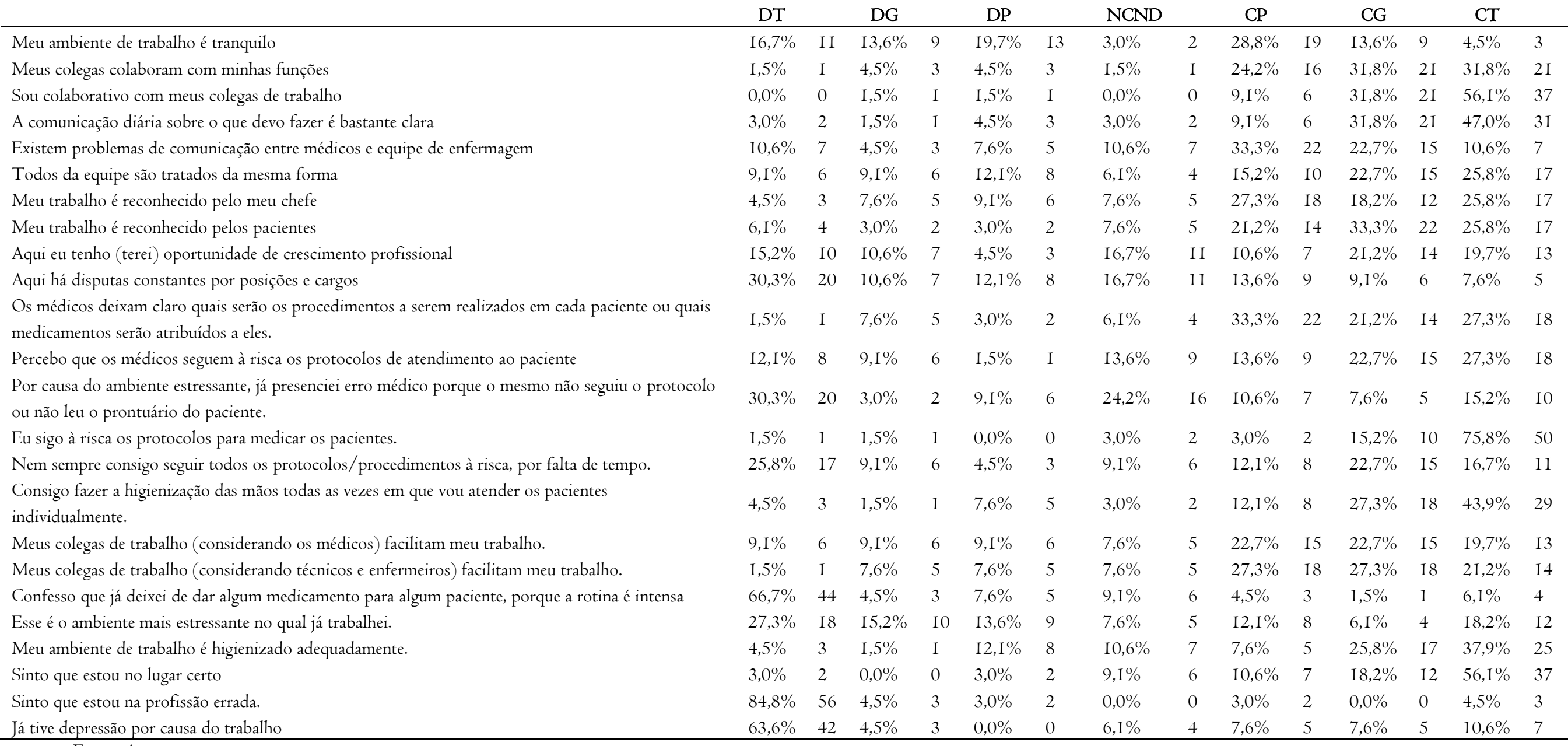
Fonte: Autores 
Um pouco mais de 50\% concorda que existe oportunidade para crescimento profissional. Um percentual de $53 \%$ não acredita que existe constante disputa por cargos enquanto que $30 \%$ concorda (em algum nível de concordância) que existe. Mais de $80 \%$ concordam que os médicos deixam claro quais serão os procedimentos a serem realizados em cada paciente ou quais medicamentos serão atribuídos a eles, $22,7 \%$ discordam em algum grau, que os médicos seguem à risca os protocolos de atendimento ao paciente, enquanto que $63,6 \%$ concordam parcialmente, em grande parte ou totalmente com essa afirmação.

Chama atenção que $33 \%$ concordam (em algum grau) que por causa do ambiente estressante, já presenciaram erro médico porque o mesmo não seguiu o protocolo ou não leu o prontuário do paciente, enquanto que $42 \%$ discordam parcialmente, em grande parte ou totalmente. Outro fato que também chama atenção é que 24,4\% não concordam, nem discordam disso, é um dos maiores percentuais de escolha por essa alternativa em relação às outras afirmativas. Mais de $90 \%$ dos entrevistados dizem seguir à risca os protocolos para medicar os pacientes. Mas, logo na afirmação seguinte, 51,5\% concordam parcialmente, em grande parte ou totalmente que nem sempre conseguem seguir todos os protocolos/procedimentos à risca, por falta de tempo. Apesar disso, mais de $80 \%$ diz conseguir fazer a higienização das mãos todas as vezes em que atendem os pacientes individualmente.

Os profissionais da enfermagem dizem concordarem (em algum grau) que seus colegas de trabalho (considerando os médicos) facilitam seu trabalho, num total de $65 \%$, enquanto que $75,8 \%$ desses profissionais concordam que seus colegas de trabalho (considerando técnicos e enfermeiros) facilitam seu trabalho. Um total de 78,8\% discorda parcialmente, em grande parte ou totalmente que já deixaram de dar algum medicamento para algum paciente, porque a rotina é intensa, $36,4 \%$ concordam que o hospital é o ambiente mais estressante no qual o profissional já trabalhou, enquanto que $56 \%$ discordam disso em algum grau. Sobre a limpeza do ambiente, 7I\% diz que o ambiente é higienizado adequadamente.

No que se refere ao exercício da profissão, 84,8 \% sentem que estão no lugar certo, 92,4\% discordam que estão na profissão errada.

Sabe-se que a saúde mental, física e emocional dos profissionais da saúde, é extremamente importante, e que a depressão é uma doença que acomete grande parte desses profissionais. No presente estudo, 25,8\% afirmaram que já tiveram depressão por causa do trabalho. De acordo com Alves et al. (2019), a depressão pode provocar grande desgaste emocional, e como consequência, comprometer o ofício dos profissionais da enfermagem nos cuidados dedicados aos pacientes, além de acarretar prejuízos à saúde mental desses trabalhadores.

Também foram rodadas com o auxílio do SPSS a média, a mediana e a moda, os resultados estão apresentados na tabela 2 .

Meu ambiente de trabalho é tranquilo.

Meus colegas colaboram com minhas funções.

Sou colaborativo(a) com meus colegas de trabalho.

A comunicação sobre o que devo fazer diariamente é bastante clara.

Existem problemas de comunicação entre médicos e equipe de enfermagem.

Todos da equipe são tratados da mesma forma pelo chefe direto.

Meu trabalho é reconhecido pelo meu chefe.

Meu trabalho é reconhecido pelos pacientes.

Aqui eu tenho (terei) oportunidade de crescimento profissional.

Aqui há disputas constantes por posições e cargos.

Os médicos deixam claro quais serão os procedimentos a serem realizados em cada

paciente ou quais medicamentos serão atribuídos a eles.

Percebo que os médicos seguem à risca os protocolos de atendimento ao paciente.

Por causa do ambiente estressante, já presenciei erro médico porque o mesmo não

seguiu o protocolo ou não leu o prontuário do paciente.

Eu sigo à risca os protocolos para medicar os pacientes.

\begin{tabular}{crr} 
Mean & Median & \multicolumn{1}{c}{ Mode } \\
\hline 3,7273 & 3,500 & 5,00 \\
5,6515 & 6,000 & $6,00^{\mathrm{a}}$ \\
6,3636 & 7,000 & 7,00 \\
5,9697 & 6,000 & 7,00 \\
4,6212 & 5,000 & 5,00 \\
4,8030 & 5,000 & 7,00 \\
5,0303 & 5,000 & 5,00 \\
5,3788 & 6,000 & 6,00 \\
4,4697 & 5,000 & 6,00 \\
3,3030 & 3,000 & 1,00 \\
5,3485 & 5,000 & 5,00 \\
& & \\
4,8485 & 5,500 & 7,00 \\
3,6515 & 4,000 & 1,00 \\
& 7,000 & 7,00
\end{tabular}

Condições de Trabalho de Profissionais da Saúde: em estudo realizado em um hospital público no noroeste do Parana 


\begin{tabular}{|c|c|c|c|}
\hline \multirow[b]{3}{*}{$\begin{array}{l}\text { Nem sempre consigo seguir todos os protocolos/procedimentos à risca, por falta de } \\
\text { tempo. }\end{array}$} & \multirow[b]{2}{*}{ Mean } & \multicolumn{2}{|c|}{ Conclusão } \\
\hline & & Median & Mode \\
\hline & 4,0758 & 5,000 & $\mathrm{I}, 00$ \\
\hline $\begin{array}{l}\text { Consigo fazer a higienização das mãos todas as vezes em que vou atender os pacientes } \\
\text { individualmente. }\end{array}$ & 5,7424 & 6,000 & 7,00 \\
\hline Meus colegas de trabalho (considerando os médicos) facilitam meu trabalho. & 4,7273 & 5,000 & $5,00^{\mathrm{a}}$ \\
\hline Meus colegas de trabalho (considerando técnicos e enfermeiros) facilitam meu trabalho. & 5,1818 & 5,000 & $5,00^{\mathrm{a}}$ \\
\hline $\begin{array}{l}\text { Confesso que já deixei de dar algum medicamento para algum paciente, porque a rotina } \\
\text { é intensa. }\end{array}$ & 2,0909 & $\mathrm{I}, 000$ & $\mathrm{I}, 00$ \\
\hline Esse é o ambiente mais estressante no qual já trabalhei. & 3,5303 & 3,000 & 1,00 \\
\hline Meu ambiente de trabalho é higienizado adequadamente. & 5,4394 & 6,000 & 7,00 \\
\hline Sinto que estou no lugar certo. & 6,0303 & 7,000 & 7,00 \\
\hline Sinto que estou na profissão errada. & 1,5000 & 1,000 & $\mathrm{I}, 00$ \\
\hline Já tive depressão por causa do trabalho. & 2,5455 & $\mathrm{I}, 000$ & 1,00 \\
\hline
\end{tabular}

a. Multiple modes exist. The smallest value is shown

Fonte: dados da pesquisa

A média refere-se ao valor que indica onde mais se concentram os dados de uma determinada distribuição de casos. Indica o valor médio observado em um certo conjunto de dados.

A mediana é o valor que se encontra mais ao meio em uma distribuição de dados qualquer, ordenada em ordem crescente. Este valor separa a metade inferior da amostra, população ou distribuição de probabilidade, da metade superior. Essa medida indica possíveis desvios em relação à média, e é utilizada para identificar possíveis desvios gerados por valores anômalos (ou fora do comum) em uma dada série de dados.

A moda é o valor que mais aparece em uma distribuição. Em alguns casos, uma certa amostra ou distribuição de dados pode apresentar mais de um valor modal. Essa medida indica qual ou quais são os valores mais comuns em um determinado conjunto de dados. Serve para identificar onde se encontra o maior número de respostas, independentemente do valor médio observado para as respostas.

Lembrando que as opções de alternativas têm 'valores' que vão de I a 7, considerando a escala likert de sete pontos: DT é discordo totalmente (I); DG - discordo em grande parte (2); DP - discordo parcialmente (3); NCND - não concordo, nem discordo (4); CP - concordo parcialmente (5); CG concordo em grande parte (6); CT - concordo totalmente (7).

Desse modo, verificando na tabela os valores da moda, podemos ver por exemplo que na primeira afirmação 'Meu ambiente de trabalho é tranquilo', a resposta que apareceu com maior frequência entre os respondentes foi a 'concordo parcialmente'. Na afirmação 'Meus colegas colaboram com minhas funções', a opção mais assinalada pelos profissionais de enfermagem foi a 'concordo em grande parte'. E assim sucessivamente, sendo possível identificar qual opção foi mais escolhida nessa pesquisa, em cada um dos itens avaliados.

$\mathrm{Na}$ sequência serão apresentados os resultados referentes às questões nas quais os respondentes deveriam apontar os fatores: que mais dificultam seu trabalho; que mais thes proporcionam satisfação; e que mais lhes causam indignação no ambiente de trabalho. No caso dessas questões (relacionadas aos gráficos I, 2 e 3 ), os respondentes poderiam marcar quantas alternativas considerassem adequadas, levando em conta a realidade do seu ambiente de trabalho. Desse modo, os percentuais, se somados, irão ultrapassar o valor de cem por cento.

Primeiro foi solicitado aos profissionais que respondessem quais são os fatores que mais dificultam o dia a dia de seu trabalho. Os resultados referentes a essa questão estão apresentados no gráfico I, a seguir.

De acordo com os dados apresentados no gráfico, o fator que mais dificulta o trabalho do profissional da saúde, é a quantidade de pacientes para atender, com $65,2 \%$, seguido de saber que meu salário não corresponde as minhas funções $5 \mathrm{I}, 5 \%$. O comportamento arrogante de alguns médicos para com a equipe de técnicos, aparece com $48,5 \%$; o descaso de alguns médicos para com os pacientes referese a $43,9 \%$; o comportamento de alguns pacientes que não querem ser medicados $36,4 \%$; a falta de alguns 
equipamentos para realização de exames de diagnóstico, 33,3\%; e o comportamento de alguns pacientes que exigem mais medicação além da prescrita, 30,3\%. Com percentuais menores do que $30 \%$ e maior que I0\%, estão: lembrar que meu salário não paga as minhas contas; a falta de material/medicamentos para atender os pacientes; a postura do meu superior; saber que não vou receber meu salário em dia; o cansaço, devido à quantidade de horas trabalhadas. Com um percentual menor que $10 \%$ aparecem: o fato de eu ter dois ou mais locais de trabalho, às vezes já chego cansado(a); o fato de que não gosto muito do que faço, mas é o único emprego que tenho no momento; e outro motivo.

\section{Gráfico I - Fatores que dificultam o trabalho do profissional}

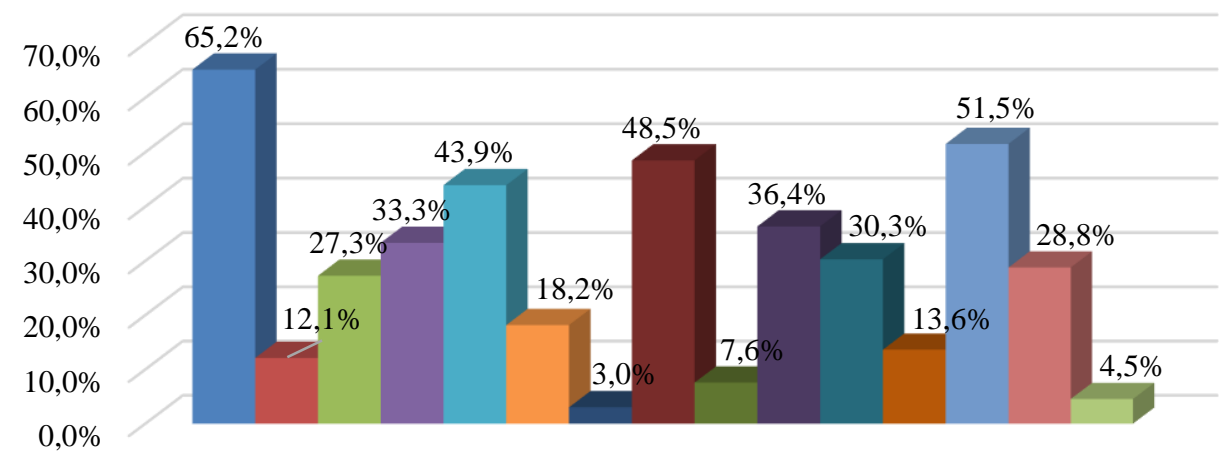

a quantidade de pacientes para atender.

- o cansaço, devido à quantidade de horas trabalhadas.

a falta de material/medicamentos para atender os pacientes.

a falta de alguns equipamentos para realização de exames de diagnóstico.

- o descaso de alguns médicos para com os pacientes.

a postura do meu superior.

- o fato de que não gosto muito do que faço, mas é o único emprego que tenho no momento.

- o comportamento arrogante de alguns médicos para com a equipe de técnicos.

口 o fato de eu ter dois ou mais locais de trabalho, às vezes já chego cansado(a).

— o comportamento de alguns pacientes que não querem ser medicados.

n o comportamento de alguns pacientes que exigem mais medicação além da prescrita.

- saber que não vou receber meu salário em dia.

— saber que meu salário não corresponde as minhas funções.

- Lembrar que meu salário não paga as minhas contas

Outro motivo

Fonte: Dados da pesquisa

Dentre os que responderam outro motivo, foram apontados como outros fatores:

"A falta de união, a arrogância de alguns médicos e superiores com os técnicos de enfermagem. Companheiros de trabalho que querem se aparecer para enfermeira". (respond. 27)

"Falta de incentivo. Só há reclamações, num setor onde tem I5 pacientes e poucos funcionários". (respond. 35)

Sabe-se que muitos sentem dificuldade na realização de atividades sob pressão, e tais atividades realizadas nessas condições podem não se concluir com o mesmo sucesso de quando realizadas num cenário tranquilo, contudo, se essas atividades se relacionam diretamente com vidas, erros podem ser fatais. Os estudos de Manyisa e Van Aswegen (2017), apontam que em hospitais públicos, as condições de trabalho não são consideradas satisfatórias. Segundo Eklöf et al. (20I4), o profissional da saúde quando 
realiza muitas atividades causadoras de estresse, seja ele causado por influência de grandes quantidades de pacientes, pouco tempo para realização delas e muita complexidade, têm sua capacidade psicológica (cuidado, concentração, boa habilidade de comunicação) corroída, contribuindo no aumento erros, que por sua vez ao serem percebidos, causam ainda mais estresse em médicos e enfermeiro. Além disso, os autores ainda destacam que a saúde mental e segurança dos pacientes e colaboradores dependem de uma boa comunicação interpessoal firmada em confiança, entendendo que rotinas, protocolos e padrões podem promover uma segurança, mas as mesmas são vulneráveis à falta de investimentos, ora na remuneração dos colaboradores ou na qualidade de treinamentos.

O gráfico 2 retrata os fatores que causam satisfação no trabalho.

\section{Gráfico 2 - Fatores de satisfação no trabalho}

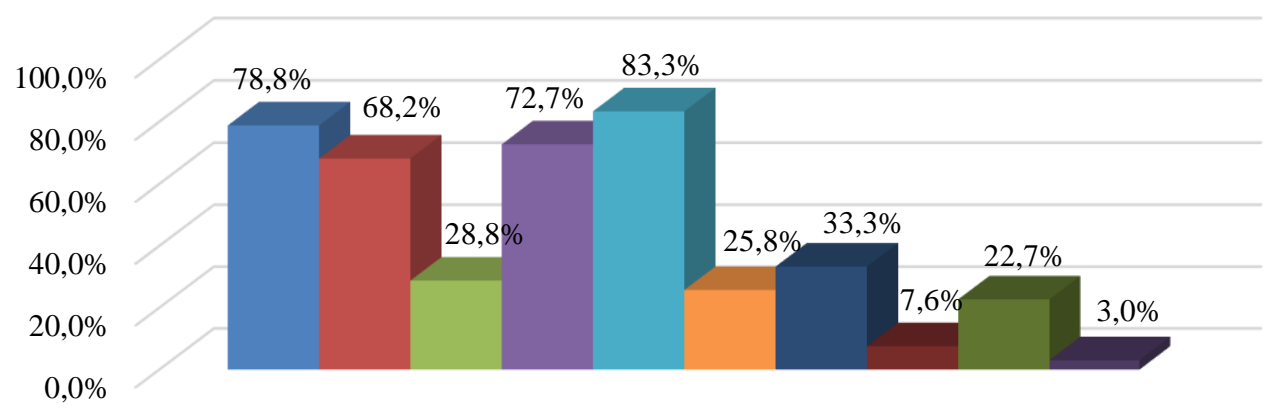

- a gratidão dos pacientes e familiares pelo trabalho realizado, ainda que o paciente não fique curado.

w ser um amigo para os pacientes enquanto ele está internado, e poder ouvi-lo.

o reconhecimento do meu trabalho pelo meu superior.

ver o paciente curado.

- saber que eu contribui para a cura do paciente.

a oportunidade de crescimento profissional que tenho aqui.

- receber meu salário em dia no final do mês.

- o fato de ser bem remunerado (a).

- saber que posso meu sustentar com o que ganho aqui.

n Outro motivo.

Fonte: Dados da pesquisa

Conforme demonstrado no gráfico 2, o fator de satisfação saber que o profissional contribuiu para a cura do paciente, aparece com um percentual de $83,3 \%$; a gratidão dos pacientes e familiares pelo trabalho realizado, ainda que o paciente não fique curado, com $78,8 \%$; ver o paciente curado com $72,7 \%$; ser um amigo para os pacientes enquanto ele está internado, e poder ouvi-lo aparece com $68,2 \%$; receber meu salário em dia no final do mês com 33,3\%; o reconhecimento do meu trabalho pelo meu superior, com 28,8\%; a oportunidade de crescimento profissional que tenho aqui com $25,8 \%$; saber que posso meu sustentar com o que ganho aqui com $22,7 \%$; o fato de ser bem remunerado (a); 7,6\%; Outro motivo $3,0 \%$.

Alguns autores apontam que um bom relacionamento entre pacientes e profissionais da saúde conseguem melhorar a autoestima/confiança de ambos no atendimento. Salários e incentivos financeiros, mesmo que importantes, ainda ficam para trás, ressaltando a importância de desenvolvimento no local de trabalho e apreço pelos pacientes, que são de grande influência para a satisfação (DERIBA, et al., 2017). 
Converso et al. (2015) entendem que em contextos caracterizados por turnos de trabalho e carga horária excessiva, onde o relacionamento com os pacientes é mais curto e superficial, os profissionais mostram níveis mais alto de desgaste e têm uma percepção menos positiva de relacionamento com pacientes.

Diante disso, é possível verificar que os maiores percentuais sobre a satisfação dos profissionais, estão relacionados aos pacientes. Esses resultados corroboram a pesquisa de Elias e Navarro (2006), na qual apontam que os profissionais se sentem satisfeitos com a melhora do paciente e a sensação do dever cumprido. No estudo de Paula et al. (2010), a melhora do paciente também aparece como um fator de satisfação profissional.

Dois respondentes optaram também por assinalar 'outro motivo', e comentar que motivo seria esse.

$$
\begin{aligned}
& \text { "Quando o paciente diz: Deus o abençoe! Essa é nossa satisfação e alegria, não tem dinheiro } \\
& \text { que pague." (respond 25). } \\
& \text { "A valorização dos pais, pelo meu serviço prestado".(respond. } 35 \text { - pediatria). }
\end{aligned}
$$

Embora dois profissionais tenham assinalado a alternativa 'outro motivo', percebe-se que tais motivos continuam vinculados ao paciente, considerando a valorização e a gratidão recebidas dos pacientes e familiares.

No gráfico 3, a seguir são apresentados os motivos de indignação no trabalho.

No gráfico 3, é possível verificar que o maior motivo de indignação no trabalho dos profissionais de enfermagem, é quando veem um paciente ser grosseiro com a equipe de saúde com um percentual de $78,8 \%$; em segundo lugar quando veem um médico dar pouca importância ao paciente, com 72,7\%; em terceiro quando percebe que um paciente é ignorado por algum colega de trabalho (considerando enfermeiros e técnicos) com $60,6 \%$. Um outro motivo que aparece com $47 \%$ é quando faltam medicamentos para os pacientes; seguido de quando faltam leitos para atender a todos os pacientes que procuram a Santa Casa que aparece com 34,8\%; quando faltam equipamentos para realização de exames com 33,3\% e 'outro motivo' aparece com I,5\%.

\section{Gráfico 3 - Motivos de indignação no trabalho}

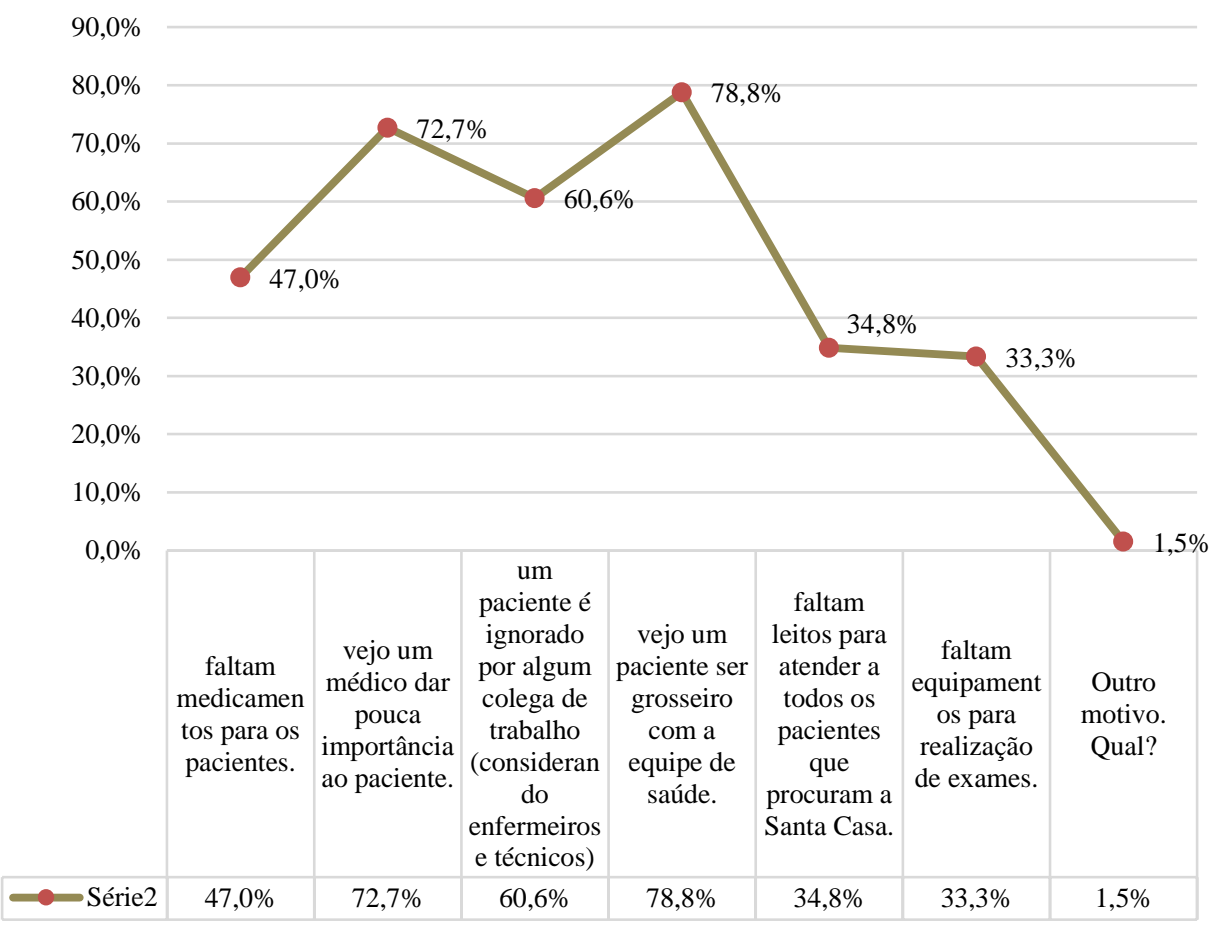

Fonte: Dados da pesquisa 
Apenas um dos respondentes escolheu a opção 'outro motivo', conforme relatado a seguir.

"Quando sou chamada a atenção pelos erros dos outros, gosto de assumir minhas ações". (respond. 35)

Ao final do formulário, havia uma questão aberta na qual os respondentes poderiam relatar o que quisessem a respeito do ambiente de trabalho que não havia sido abordado nas questões anteriores. Nesse questionamento, encontrou-se os seguintes relatos, apresentados no quadro I.

Quadro I - Relatos dos respondentes sobre o ambiente de trabalho

\begin{tabular}{|c|c|}
\hline Respondentes & Relatos \\
\hline Respondente I & $\begin{array}{l}\text { "Que trabalho numa empresa filantrópica que precisa de ajuda. Porém, eu não trabalho por trabalhar. Eu vivo } \\
\text { para ajudar as pessoas". }\end{array}$ \\
\hline Respondente II & $\begin{array}{l}\text { "Faz-se necessário mais capacitações para técnicos novos na instituição, pois vejo que alguns técnicos não estão } \\
\text { bem preparados para fazer as atividades". }\end{array}$ \\
\hline Respondente I2 & $\begin{array}{l}\text { "Fico indignada quando o médico reclama do número de pacientes para atender. Ninguém escolhe ficar doente, } \\
\text { ninguém quer ficar num hospital. Se não quer atender, não venha trabalhar num hospital. Isso é tanto para } \\
\text { médicos quanto para técnicos e enfermeiros. Às vezes, só um sorriso já faz a doença ir embora e fazer os } \\
\text { funcionários trabalharem melhor. E vale todo o esforço, não precisamos nem de salário maior." }\end{array}$ \\
\hline Respondente I9 & "Que tivesse mais funcionários nos setores para fazer o trabalho melhor". \\
\hline Respondente 25 & "Sobrecarga de trabalho, muitos pacientes por funcionários, falta de comunicação do superior". \\
\hline Respondente 29 & $\begin{array}{l}\text { "Acho que a coordenação deveria ser mais compreensível com os técnicos, vendo o quanto trabalhamos e nos } \\
\text { esforçamos para o melhor atendimento, pois nossa classe se sente desvalorizada diante de tantas exigências e } \\
\text { muito pouco reconhecimento. Temos que dar conta de tantos pacientes para } 2 \text { ou } 3 \text { funcionários, enquanto } \\
\text { que chefes para mandar e exigir sobram no hospital". }\end{array}$ \\
\hline Respondente 32 & $\begin{array}{l}\text { "É um ambiente estressante e de fluxo grande. Quando o mesmo está tranquilo, o funcionário deixa o setor } \\
\text { para suprir a falta de funcionário em outro setor. Dificilmente conseguimos tirar I hora de descanso nos } \\
\text { plantões de } \mathrm{I} 2 \text { horas. A falta de segurança, e a facilidade que as pessoas de fora podem ter acesso a entrar neste } \\
\text { setor me assusta e preocupa". }\end{array}$ \\
\hline Respondente 33 & "Falta de funcionários no setor, muita sobrecarga, e a questão também da insalubridade". \\
\hline Respondente 35 & $\begin{array}{l}\text { "Adoro trabalhar aqui, a cada dia tento melhorar mais, mas fico desestimulada devido aos erros dos outros } \\
\text { funcionários que fazem errado, e dizem para nós que: tentamos fazer o correto". }\end{array}$ \\
\hline Respondente 42 & "A falta de funcionários sobrecarrega muito a equipe, há muitos profissionais sem prática, sem conhecimento". \\
\hline Respondente 52 & $\begin{array}{l}\text { "A ouvidoria caso feito reclamações da equipe pelo paciente, e a situação não ser verdadeira.... A gente fica sem } \\
\text { se defender quanto a isso". }\end{array}$ \\
\hline Respondente 54 & $\begin{array}{l}\text { "Grande demanda de pacientes e poucos funcionários na instituição. Supervisores deveriam ouvir mais seus } \\
\text { técnicos e enfermeiros. A instituição deveria rever a saúde mental de seus funcionários. A instituição devia dar } \\
\text { incentivo aos seus funcionários. Há funcionários estressados cada vez mais por conta do que citei." }\end{array}$ \\
\hline Respondente 55 & $\begin{array}{l}\text { "Algo que realmente me desmotiva é chegar no trabalho e perceber a grande quantidade de pacientes para tão } \\
\text { poucos funcionários. Pois, com a grande demanda, acaba que não damos a devida atenção e cuidados aos } \\
\text { pacientes. Não somos reconhecidos como deveríamos. O aumento de funcionários seria a solução para um } \\
\text { trabalho menos estressante." }\end{array}$ \\
\hline Respondente 59 & $\begin{array}{l}\text { "Grande demanda de pacientes com cotas acima do permitido pelo Corem, que é de } 20-27 \text { pacientes, poucos } \\
\text { funcionários, descaso dos supervisores que não são humanizados com os funcionários. Falta saúde mental para } \\
\text { os funcionários." }\end{array}$ \\
\hline
\end{tabular}

Fonte: Dados da pesquisa 
Em todos os países analisados, a carga física do pessoal de enfermagem é alta e, por sua vez, excede os profissionais médicos (ORGANIZAÇÃO PANAMERICANA DA SAÚDE, 2012).

\footnotetext{
"Gostaria que avaliassem melhor as reclamações da ouvidoria porque somos advertidos muitas vezes por reclamações falsas e mentirosas dos pacientes". (respond 60)

"Apesar dos acontecimentos, só tenho a agradecer pela família Santa Casa, que me deu a oportunidade. Aqui fiz muitos amigos, aprendi muitas coisas boas e ainda tenho muita coisa para aprender. Obrigada". (respond 6I).

"Gosto do local de trabalho, pois acho que é uma grande oportunidade de crescimento profissional e pessoal, embora tenha algumas dificuldades devido à pouca experiência. Trabalhar aqui me permite o desenvolvimento como pessoa." (respond 66)
}

Nesses relatos, pode-se perceber que além das preocupações que foram aqui expressas, existem também expressões de sentimentos de agradecimento.

Em resumo, os apontamentos referem-se à necessidade de capacitação, sobrecarga de trabalho, excesso de pacientes para atender, necessidade de maior quantidade de funcionários, má comunicação do superior para com a equipe, ambiente estressante, falta de segurança, erros de funcionários, a não possibilidade de defesa em relação às reclamações que chegam a ouvidoria, supervisores não ouvem técnicos e enfermeiros, falta de reconhecimento pelo trabalho realizado. Todas essas situações provocam desmotivação dos profissionais em relação às suas atividades laborais e ao desempenho de suas funções.

\section{CONCLUSÕES}

Considerando que o objetivo primordial era identificar como as condições de trabalho afetam o desempenho das tarefas diárias dos profissionais da saúde, apresenta-se as conclusões do estudo.

Pode-se afirmar que existe colaboração entre os respondentes no que se refere às suas tarefas diárias. A maior parte desses profissionais afirmam que sabem exatamente o que devem fazer no desempenho de suas funções. Entretanto, parece que nem sempre existe uma comunicação eficiente entre equipe médica e profissionais de enfermagem. Vale ressaltar que pelo menos 20 profissionais (30\%) não sentem que existe equidade em relação ao tratamento que recebem. Seria importante que o gestor da equipe estivesse atento a essa questão, a fim de identificar as possíveis falhas na comunicação e/ou nos aspectos comportamentais para com sua equipe.

A falta de tempo é recorrente em um hospital que atende uma grande quantidade de pacientes diariamente, e isso se reflete no atendimento aos usuários, tendo em vista que nem sempre é possível seguir à risca todos os protocolos/procedimentos padrão, conforme aparece nos resultados. E esse é um fator que podem comprometer, em parte, a segurança do paciente. Em relação ao trabalho realizado, percebese nos resultados que há um grande percentual de profissionais que sentem estar no lugar certo, exercendo a profissão certa. No entanto, é importante considerar que alguns já tiveram depressão por conta da profissão.

Como fatores que mais dificultam o trabalho dos profissionais aparecem respectivamente: a carga de trabalho; ter uma remuneração que não condiz com as funções exercidas; o comportamento arrogante e o descaso de alguns médicos para com a equipe técnica e para com os pacientes.

A satisfação dos profissionais da enfermagem está especialmente vinculada à cura dos pacientes, à gratidão recebida dos mesmos e de suas famílias, à oportunidade de ouvi-los e de ser considerado amigos desses pacientes.

Existem diversos motivos pelos quais esses profissionais sentem-se indignados, tais como: quando presenciam um paciente agir com grosseria com a equipe de saúde; quando veem um médico não dar muita importância ao paciente; quando um paciente é ignorado por algum colega de trabalho; e ainda quando faltam medicamentos necessários para o tratamento dos pacientes. 
Desse modo, acredita-se que o presente estudo também pode contribuir de modo gerencial. A partir dos dados apresentados, os gestores poderão planejar e direcionar melhor suas ações, visando contribuir para o bem-estar dos colaboradores e dar maior atenção aos aspectos comportamentais que afetam o trabalho desses profissionais no hospital.

Afinal, oferecer condições adequadas de trabalho, é essencial para o pleno desempenho das atividades dos profissionais da saúde (OLIVEIRA; PEDRAZA, 20I9).

Embora o intuito não seja generalizar os resultados, apontamos como um dos fatores limitantes, o fato da pesquisa ter sido limitada a um hospital. Um estudo com múltiplos casos poderia oferecer dados diferentes dos encontrados nesse estudo.

Como direções para pesquisas futuras, esse estudo poderia ser replicado em outros hospitais públicos, em diferentes cidades, estados e/ou países. A pesquisa também poderia ser realizada em hospitais privados.

\section{REFERÊNCIAS}

ALVES, et al. Depressão entre profissionais de enfermagem no contexto hospitalar: uma revisão de literatura. Brazilian Journal of Surgery and Clinical Research - BJSCR, v. 27, n.3, p.I4I-I46, 2019.

BARCAUI, A.; LIMONGI-FRANCA, A. C. Estresse, enfrentamento e qualidade de vida: um estudo sobre gerentes brasileiros. Revista de Administração Contemporânea, v. I8, n. 5, p. 670-694, 2014.

BOECK, K. H.; HIITTL, N.; CEMBRANEL, P.; TASCHETTO, L. A Segurança do Paciente Devido os Riscos da Sobrecarga de Trabalho dos Enfermeiros. Revista de Administração Hospitalar e Inovação em Saúde, v. I6, n. 3, p. I5-27, 2019.

BRUNETTO, Y.; XERRI, M.; FARR-WHARTON, B. Comparing the role of personal and organisational support on the innovative behavior of frontline healthcare workers in Australia and the United States. Australian Journal of Public Administration. Edição Especial, p. I-I9, 2020.

CANALES-VERGARA, M.; VALENZUELA-SUAZO, S.; PARAVIC-KLIJN, T. Condiciones de trabajo de los profesionales de enfermería en Chile. Enfermería Universitaria, v. I3, n. 3, p. I78-I86, 2016.

CARVALHO, D. P. de et. al. Cargas de trabalho e a saúde do trabalhador de enfermagem: revisão integrativa. Cogitare Enfermagem, v. 22, n. I, p. OI-II, 2017.

CONVERSO, D. et al. Do positive relations with patients play a protective role for healthcare employees? Effects on patients' gratitude and support in nurses' burnout. Frontiers in Psychology, v. 6, n. I, p. 2-II, 2015.

COSTA, M. T. P.; BORGES, L. O.; BARROS, S. C. Condições de trabalho e saúde psíquica: um estudo em dois hospitais universitários. Revista Psicologia: Organizações e Trabalho, v. I5, n. I, p. 43-58, 2015.

DERIBA, B. K. et al. Health professionals' job satisfaction and associated factores at public health centers in West Ethiopia. Human Resources for Health. V. I5, n. I, p. I-7, 2017.

DIAS, E. C. Condições de trabalho e saúde dos médicos: uma questão negligenciada e um desafio para a Associação Nacional de Medicina do Trabalho. Rev Bras Med Trab, v. I3, n. 2, p. 60-68, 2015. 
EKLÖF, M. et al. Organizational and social-psychological conditions in healthcare and their importance for patient and staff safety. A critical incident study among doctor and nurses. Safety Science, v.70, n. I, p. 2II-22I, 2014.

ELIAS, M. A.; NAVARRO, V. L. A relação entre o trabalho, a saúde e as condições de vida: negatividade e positividade no trabalho das profissionais de enfermagem em um hospital escola. Revista LatinoAmericana de Enfermagem, v. I4, n. 4, p. 517-525, 2006.

MACIEL, R. H. M. O.; SANTOS, J. B. F.; RODRIGUES, R. L. Condições de trabalho dos trabalhadores da saúde: um enfoque sobre os técnicos e auxiliares de nível médio. Revista Brasileira de Saúde Ocupacional, v. 40, n. I3I, p. 75-87, 2015.

MANYISA, Z. M; VAN ASWEGEN, E. J. Factors Affecting Working Conditions in Public Hospitals: A Literature Review. International Journal of Africa Nursing Sciences, v. 6, n. I, p. 28-38, 2017.

MARQUES, A. L. N. et al. Qualidade de vida e contexto de trabalho de profissionais de enfermagem da Estratégia Saúde da Família, Rev Rene. v. I6, n. 5, p. 672-68I, 2015.

OLIVEIRA JR., R. G. et. al., Condições de trabalho das Equipes de Saúde da Família do município de Petrolina-PE: percepção dos profissionais de saúde. O Mundo da Saúde, v. 37, n. 4, p. 433-438, 2013.

OLIVEIRA, M. M. de; PEDRAZA, D. F. Contexto de trabalho e satisfação profissional de enfermeiros que atuam na Estratégia Saúde da Família. Saúde Debate, v. 43, n. I22, p. 765-779, 2019.

ORGANIZAÇÃO PANAMERICANA DE SAÚDE. Estudio comparativo de las condiones de trabajo y salud de los trabajadores de la salud en Argentina, Brasil, Costa Rica y Perú. Washington, D. C.: OPS, 2012.

PAULA, G. S. de et. al. O sofrimento psíquico do profissional de enfermagem da unidade hospitalar. AQUICHAM, v. I0, n. 3, p. 267-279, 2010.

SORATTO, J. et al. Insatisfação no trabalho de profissionais da saúde na estratégia saúde da família. Texto Contexto Enferm., v. 26, n. 3, p. 2-II, 2017.

WAGNER, A. et al. Healthcare professionals' perspectives on working conditions, leadership, and safety climate: a cross-sectional study. BMC Health Services Research, v. I9, n. I, p. I-I4, 2019. 